\title{
Current Status and Prospects of Research on Gamification in the Field of Basic Education in China
}

\section{Xu Yan}

Normal College of Yanbian University, 133002 Yanji, Jilin Province

Abstract: With the continuous upgrading of educational theories, people have realized that enhancing students' interest in learning is the best way to improve students' learning efficiency, and gamified learning methods are one of the most effective and innovative teaching methods. Development is very important. This article mainly analyzes the current situation of gamified learning in the field of basic education in our country, and puts forward some teaching reform suggestions in response to the problems in actual teaching, hoping to promote the development of gamified learning.

Keywords: Basic education; game-based learning; current research; future prospects

In recent years, innovative teaching methods using gamified learning in the field of basic education have received widespread attention from all walks of life. Because it can effectively stimulate students' enthusiasm for learning, enhance students' innovative ability, and play a very active role in promoting education reform, it is deeply loved by students and teachers. Combining years of experience in basic education, the author analyzes in detail the current situation of gamified learning in the field of basic education in my country, and proposes some superficial suggestions for the development of gamified learning in the future according to the problems that have been revealed, hoping to provide some improvements to the majority of teaching workers Inspired by gamified learning.

\section{The status quo of gamified learning in the domestic basic education field}

The domestic basic education field has never stopped the research on gamified learning. From the analysis of the current development situation, gamified learning has obtained certain breakthroughs in all aspects of research, but there are still certain limitations in the application of theory and practice. The specific characteristics can be expressed as the following:

\subsection{The theoretical research on how to integrate education and entertainment is lacking}

The essence of game-based teaching is still teaching. Games are only tools and means to assist teaching and improve teaching efficiency. In practical teaching applications, how to perfectly integrate the educational and entertaining properties to avoid that the playability is greater than the educational nature and cause students to indulge in games and lose their educational significance, or the educational nature is greater than the entertaining nature and make students lose their interest in continuing to play learning. Issues that gamified learning researchers should focus on. However, this theoretical research is still in a vacant state. In order to maintain the effectiveness of gamified learning, theoretical research that naturally integrates education and entertainment should be paid more attention.

\subsection{Gamification learning evaluation mechanism needs to be improved}

In the final analysis, game-based learning is a way to motivate and guide students to learn actively. In order to enhance the effect of this learning method, effective evaluation of learning content after the game is completed can consolidate the learning effect and enhance the effectiveness of learning Important role. However, as far as the application and development of gamified learning are concerned, there are serious deficiencies in the final learning 
evaluation link. Students rarely get effective, comprehensive and scientific evaluation after game learning, which makes students have a better understanding of themselves It is not comprehensive enough, and it loses part of the improvement effect brought by gamified learning, which is very unfavorable to the development of gamified learning in the future.

\subsection{The coordination and unity of knowledge, skills, and emotions in gamified learning should be emphasized}

In addition to specific knowledge learning, the goal of game-based learning should also allow students to improve their understanding and cognition of emotions, attitudes and values during the game. The biggest difference between gamified learning and traditional learning is that it can help students build an immersive game environment. Games can provide students with opportunities to interact with other participants, and can build different game situations according to learning needs. Therefore, in order to To better highlight the advantages of gamified learning, knowledge learning, skill training and emotional guidance should be integrated to improve the overall quality of learners.

\section{Prospects for the development of gamified learning in the field of basic education in my country}

\subsection{Taking students as the center, considering the learning characteristics of different students}

Basically, the students facing the field of basic education have the characteristics of being hyperactive and eager to learn, but unable to concentrate for a long time, and because of the difference in living and learning environment, students have very big differences in personality. In gamified learning, we should pay attention to this point, that is, truly student-centered, taking into account the learning characteristics of different students, using dynamic game mechanisms to meet the learning needs of different forms of students as much as possible, balancing teaching and gameplay, and allowing students It is possible to maintain a long-term commitment to gamified learning. Therefore, in the future development of gamified learning, researchers should consider more from the perspective of humanity, constantly summarize students' feedback on gamified learning, and design more diversified game learning methods to enhance gamification Effectiveness of learning.

\subsection{Improve the evaluation mechanism and enhance the effect of gamified learning}

Game-based learning can greatly enhance students' enthusiasm for learning, and can help students have a very good immersive experience in a short time. However, in order to ensure subsequent learning effects and consolidate students' knowledge gained in game learning, it should also be structured well. The specific learning evaluation mechanism should be as follows: First, for teaching game applications, an information system evaluation program can be constructed after the game, and objective and effective evaluations can be made based on students' reactions in the game. Second, you can track and evaluate students, and evaluate their comprehensive ability in detail based on the results of multiple games. Third, games can be evaluated in terms of usability, content, entertainment, and interactivity to improve the quality of educational games and promote the sound development of gamification teaching.

\subsection{Pay attention to interaction design in gamified learning}

The purpose of gamification teaching is not only to improve students' knowledge and abilities, but more importantly, to let students experience different learning methods in games, and use the immersive interactive experience in games to deepen their emotions, skills, and values. Correct understanding. Therefore, in the development of gamified learning in the future, attention should be paid to the internal interactive design of educational games, gradually allowing students to experience different happiness in games, enhancing students' loyalty to games, and turning students' learning behavior into a self-motivation. This way, students can develop good habits of self-learning to the maximum extent, and effectively improve the teaching effect of gamified learning.

\section{Concluding remarks}

Gamification learning has a very active educational role in the field of basic education. It can not only enhance students' learning enthusiasm and stimulate their interest in learning, but also use the interactive nature of games to help students further optimize their cognition of emotions, skills and values. . With the continuous development of the gam- 
ified learning model, this entertaining and entertaining learning method will be better developed and improved, so that gamified learning can better serve basic education and students' independent learning.

\section{References}

1. Tang Lijie. The current situation and analysis of gamified learning research in the past ten years in China [J]. China Education Information, 2015, 000(005): 23-25.

2. Zhang Jing, Fu Gangshan, Zheng Xin. Current Status and Enlightenment of International Gamification Language Learning Research[J]. Audio-visual Education Research, 2018, 039(002):93-97.

3. Zhu Shiming, Wang Tian. An Empirical Study on Gamification Learning in my country's Basic Education[J]. Digital Education, 2018(04):50-55.

4. Bao Xueying, Zhao Yuxiang. Research progress and prospects of game-based learning[J]. Audio-visual Education Research, 2015(8):45-52. 